\title{
Clouds come floating into my life from other days no longer to shed rain or usher storm but to give colour to my sunset sky
}

\section{DOI: $10.7861 /$ clinmed.ed.21.4.1}

The quote of the title is from Stray Birds, a book of poems by Rabindranath Tagore. ' The imagery of trying to find silver linings after the storm of COVID-19 is reflected in this tiny verse and in some of the manuscripts in this edition of Clin Med. The anticipated recovery of services in health systems following the peak waves of the pandemic over the last 18 months is about managing not just restoration of prior services and the backlog of cases, but also adaptation to new challenges posed by COVID-19 and its consequences. One of these is the consequences for patients who have had the illness, and we are pleased to publish a large report of the symptoms and health needs in this cohort. Taylor and colleagues report on over 500 patients who had been admitted to hospital with acute COVID-19 pneumonia and 130 community long-COVID referrals. ${ }^{2}$ The size of the dataset has allowed the authors to stratify outcomes by the severity of initial COVID-19 pneumonia. As a teaser ahead of reading the paper, you may want to speculate on the utility of this stratification on predicting symptom burden at 3 months post-presentation. The implications for commissioning and coordinating care for this patient group who experience a wide range of symptoms are drawn out by the authors.

Another learning from the pandemic is highlighted by Hurlow et al, namely the potential to optimise advance care planning for acutely ill patients. ${ }^{3}$ Clinicians were encouraged to undertake timely, patient-centred conversations addressing this complex issue, and the authors confirm that using an electronic tool to help support these recommendations can markedly improve practice in terms of practice and documentation. Confirmation that this continues beyond the pandemic needs to be the future focus.

The pandemic exposed the societal inequalities that result in adverse health outcomes, and people living with disability were a vulnerable group. There are two pieces in this edition dealing with the challenge of deafness and communication with health professionals. One in five people in the UK are deaf, defined as experiencing hearing loss greater than 25 decibels. Harris et al document the barriers to accessing care and the communication difficulties in consultations. ${ }^{4}$ The importance of tailoring services for deaf patients is highlighted by their documenting the difficulty experienced by deaf people with cognitive symptoms in obtaining an accurate diagnosis prior to attending their specialist clinic. The clinic improved communication for patients and accessibility to specialist investigations, ensuring diagnostic accuracy and overall reducing health inequality for this population. The piece complements this month's foundation column outlining a practical guide to optimise communication with deaf patients. ${ }^{5}$

This editorial is written at a moment when the NHS is seeing unprecedented activity in terms of emergency admissions across the UK. Organisations find themselves struggling to meet their newly established recovery targets due to bed shortages arising from emergency admission. There is much to learn from the well documented literature on reduced emergency admissions during the peak wave of COVID-19, and a paper by Daniels and colleagues from Cambridge is especially timely, therefore. ${ }^{6}$ The findings of the study identify that patients with 'medically unexplained symptoms' who attended emergency departments frequently were more likely to present. Ahead of reading the paper, you may want to speculate what symptom presentations were commonest in this cohort, but a key message of the data is that these patients were sufficiently distressed by their complaints to present to hospital at a time when admissions among other patient groups had fallen by one-third. The publication is in harmony with the special edition of Clin Med from January of this year looking at presentation and management of functional disorders, stressing the importance of holistic service provision for this long-suffering and occasionally marginalised patient group. .

Anton Emmanuel Editor-in-chief

\section{References}

1 Tagore R. Stray Birds. New York: The Macmillan Company, 1917.

2 Taylor RR, Trivedi B, Patel N et al. Post-COVID symptoms reported at asynchronous virtual review and stratified follow-up after COVID-19 pneumonia. Clin Med 2021;21:e384-91.

3 Hurlow A, Wyld L, Breen A. An evaluation of advance care planning during the COVID-19 pandemic: a retrospective review of patient involvement in decision making using routinely collected data from digital ReSPECT records. Clin Med 2021;21:e395-8.

4 Harris MJ, Au D, Judd K et al. Evaluation of a specialist cognitive clinic for the Deaf community. Clin Med 2021;21:e375-9.

5 Abou-Abdallah M, Lamyman A. Exploring communication difficulties with deaf patients. Clin Med 2021;21:e380-3.

6 Daniels NF, Ridwan R, Barnard EDB, Amanullah TM, Hayhurst C. A comparison of emergency department presentations for medically unexplained symptoms in frequent attenders during COVID-19. Clin Med 2021;21:e399-402.

\section{Members of the editorial board}

$\begin{array}{ll}\text { Cono Ariti } & \text { Kate Evans } \\ \text { Paul Belcher } & \text { Laura Ferrigan } \\ \text { Tim Chevassut } & \text { Tevfik Ismail } \\ \text { Tahseen Chowdhury } & \text { Vikas Kapil } \\ \text { Richard Corbett } & \text { Neelam Kumar } \\ \text { Elaine Dennison } & \text { Yash Mahida } \\ \text { Albert Edwards } & \text { Chris Marguerie } \\ \text { Anton Emmanuel } & \text { Martin McKee }\end{array}$

Andrew Medford Mehool Patel Gerrard Phillips Sushma Saksena Philip Smith Angela Star Cameron Swift Rhys Thomas
Trainee associate editors: Tessa Cacciottolo Rajan Pooni Anenta Ramakrishnan

Trainee column editor: Adam Truelove 